OPEN ACCESS

Edited by:

lan Marriott,

University of North Carolina at Charlotte, United States

Reviewed by:

Lu Huang,

University of Arkansas for Medical Sciences, United States

Roberta Olmo Pinheiro,

Fundação Oswaldo Cruz (Fiocruz),

Brazil

*Correspondence:

Huanbin Xu

hxu@tulane.edu

Specialty section:

This article was submitted to Microbial Immunology,

a section of the journal

Frontiers in Microbiology

Received: 10 February 2021

Accepted: 31 May 2021

Published: 28 June 2021

Citation:

Wang X, Mehra S, Kaushal D, Veazey RS and Xu H (2021) Abnormal

Tryptophan Metabolism in HIV and Mycobacterium tuberculosis

Infection

Front. Microbiol. 12:666227. doi: 10.3389/fmicb.2021.666227

\section{Abnormal Tryptophan Metabolism in HIV and Mycobacterium tuberculosis Infection}

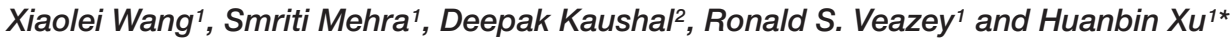 \\ ${ }^{1}$ Division of Comparative Pathology, Tulane National Primate Research Center, Tulane University School of Medicine, \\ Covington, LA, United States, ${ }^{2}$ Southwest National Primate Research Center, Texas Biomedical Research Institute, \\ San Antonio, TX, United States
}

Host metabolism has recently gained more attention for its roles in physiological functions and pathologic conditions. Of these, metabolic tryptophan disorders generate a pattern of abnormal metabolites that are implicated in various diseases. Here, we briefly highlight the recent advances regarding abnormal tryptophan metabolism in HIV and Mycobacterium tuberculosis infection and discuss its potential impact on immune regulation, disease progression, and neurological disorders. Finally, we also discuss the potential for metabolic tryptophan interventions toward these infectious diseases.

\section{Keywords: tryptophan metabolism, indoleamine 2, 3-dioxygenase, HIV, Mycobacterium tuberculosis, tryptophan metabolites}

\section{INTRODUCTION}

Human immunodeficiency virus (HIV) is characterized by the massive loss of CD4 $+\mathrm{T}$ cells, functional impairment of immune cells, disruption of the lymphoid tissues, and chronic activation (Veazey et al., 1998; Brenchley et al., 2006; Sankaran et al., 2008; Xu et al., 2013; Estes et al., 2018; Wang and Xu, 2018). Antiretroviral therapy (ART) has dramatically reduced HIV-1 replication and viremia, yet residual low-level replication-competent proviral reservoirs remain functional in a latent state, resulting in lifelong infection and viral rebound once ART is discontinued (Barouch and Deeks, 2014; Ventura, 2020). Therefore, the intact proviral reservoirs are the major obstacle in a cure for HIV infection. On the other hand, tuberculosis (TB) is caused by Mycobacterium tuberculosis $(M t b)$, which induces persistent pulmonary inflammation and multi-organ necrosis with a high risk of mortality and morbidity worldwide (Adigun and Singh, 2020; Kim et al., 2020). Strikingly, indoleamine 2,3-dioxygenase 1 (IDO1) activity is significantly elevated in both HIV and Mtb infection, correlating with AIDS and TB diseases (Favre et al., 2010; Drewes et al., 2015; Gostner et al., 2015; Jenabian et al., 2015; Routy et al., 2015; Dagenais-Lussier et al., 2016; duGyamfi et al., 2017; Gautam et al., 2018; van Laarhoven et al., 2018). There are three rate-limiting enzymes that catalyze tryptophan (Trp) to generate metabolites along the kynurenine (Kyn) pathway (KP), including Trp IDOs (TDO; regulator of the systemic levels of Trp), IDO1 (high enzyme activity and predominant tissue distribution), and IDO2 (proinflammatory responses, distribution in liver and neurons) (Rodriguez Cetina et al., 2017). IDO1 contributes to intestinal homeostasis (Alvarado et al., 2019), because Trp metabolites [L-Kyn and kynurenic acid (KYNA)] act as natural ligands and in signaling of aryl hydrocarbon receptor (AhR), involving tolerance

Abbreviations: AIDS, acquired immunodeficiency syndrome; ART, antiretroviral therapy; HIV, human immunodeficiency virus; IDO, indoleamine 2,3-dioxygenase; Kyn, kynurenine; Mtb, Mycobacterium tuberculosis; SIV, simian immunodeficiency virus; TB, tuberculosis; Trp, tryptophan. 
in inflammation (DiNatale et al., 2010; Pallotta et al., 2011; Bessede et al., 2014). However, overexpression of IDO1 might be implicated in immunosuppression (Mandi and Vecsei, 2012; Schmidt and Schultze, 2014; Dagenais-Lussier et al., 2016) or neurotoxicity (Campbell et al., 2014; Braidy and Grant, 2017; Lovelace et al., 2017). Trp is an essential amino acid to regulate host immunity, inflammation, bacterial killing, and neurotransmission. In addition to primary KP pathway ( $\sim 95 \%)$, Trp could also be catalyzed by alternative Trp hydroxylase (TPH) that converts Trp metabolism to produce melatonin and serotonin $(\sim 5 \%)$ as monoamine neurotransmitter for neuroprotection neurotransmitters (Claeysen et al., 2015; Bethea et al., 2017) or other metabolites as anti-inflammatory modulators (Wu et al., 2014). The KP may competitively dampen the $\mathrm{TPH} /$ serotonin pathway, likely resulting in preferential immunosuppressive and neurodegenerative relevance (Meltzer et al., 1998; Ruhe et al., 2007; Bethea et al., 2017). The balance of Trp metabolism is thereby critical for physiological function. Here, we summarize advances and recent findings of Trp metabolism, IDO activity, and outcomes in HIV/Mtb infection and discuss the possible intervention strategies in Trp metabolic abnormalities.

\section{TRYPTOPHAN METABOLISM IN THE HIV/SIV INFECTION}

HIV infection has profound effects on the immune system, as indicated by compromises in host immunity and neurological disorders (Xu et al., 2013; Eggers et al., 2017), accompanied by microbial translocation and persistent inflammation (Douek et al., 2009). In the context of HIV infection, HIV infection upregulates IDO expression by HIV tat, nef, and proinflammatory mediators (Smith et al., 2001; Schroecksnadel et al., 2007), which promote Trp degradation to KP to generate various Kyn intermediate metabolites (Huengsberg et al., 1998; Murray, 2003b). Of these, increased Kyn and its downstream metabolites may play an opposite role in infectious diseases, e.g., Kyn-associated immunosuppression (T-cell dysfunction and exhaustion, and Treg differentiation) (Curti et al., 2010; Mandi and Vecsei, 2012; Schmidt and Schultze, 2014) and dysbiosis of gut microbiota (Vujkovic-Cvijin et al., 2013) and neuroactive intermediates picolinic acid, KYNA, and nicotinamide adenine dinucleotide (NAD)-associated neuroprotective effects (Baran et al., 2000; Badawy, 2017) or 3-hydroxykynurenine/3-HK, quinolinic acid (QUIN)-mediated neurotoxicity and neurological disorders (Cervenka et al., 2017; Lovelace et al., 2017). Early initiation of ART normalizes plasma Trp catabolism and immune activation but does not improve gut mucosal dysfunction in HIV infection (Jenabian et al., 2015). Given that persistent inflammation and gut dysbiosis still occur even during long-term virologic suppression by ART (Bandera et al., 2018), elevated IDO activity and subsequent Kyn derivatives may maintain gut Th17 loss and neurocognitive dysfunction (Jenabian et al., 2013; Vujkovic-Cvijin et al., 2013; Keegan et al., 2019). In fact, ART shows mild to no impact on the changes of plasma Trp or K/T ratio (IDO activity) in people living with HIV
(Byakwaga et al., 2014; Routy et al., 2015; Keegan et al., 2019). Conversely, quite a number of HIV-infected patients on ART still suffer from HIV-associated neurocognitive disorders, correlating with elevated IDO activity and Kyn production and loss of serotonin (Ferrell and Giunta, 2014; Drewes et al., 2015). Further, elevated quinolinic acid and serotonin losses in the cerebrospinal fluid (CSF) of simian immunodeficiency virus (SIV)-infected rhesus macaques are only partially resolved with ART (Drewes et al., 2015). Our preliminary data indicate that SIV infection induces plasma IDO activity and downstream metabolite Kyn throughout viral infection (Figures $\mathbf{1 A}, \mathbf{B}$ ). It is reported that tetrahydrobiopterin (BH4), an essential cofactor for TPH, and exogenous $\mathrm{BH} 4$ treatment potentially rescue $\mathrm{T}$-cell responses by suppression of Kyn production (Cronin et al., 2018). Our studies also showed that BH4 feeding significantly reduced levels of Kyn and IDO activity that were typically elevated during SIV infection, yet there were no effects on the plasma viral load (data now shown). These findings suggest that HIV/SIV infection may induce elevation of both IDO activity and Kyn production, likely involved in immune regulation, yet further investigations are needed to understand the abnormalities in Trp metabolism induced by HIV/SIV infection. Abnormalities of Trp metabolism, induced by the persistent inflammation, are probably linked to pathological outcomes in HIV infection (Schroecksnadel et al., 2008; Keegan et al., 2016; Lovelace et al., 2017; Babu et al., 2019). Notably, IDO activity is the checkpoint that is positively associated with size and persistence of HIV reservoirs (Alzahrani et al., 2019; Chen et al., 2019). However, current 1-methyl-D-tryptophan (D1MT; IDO inhibitor) administration does not effectively block IDO activity and reduce downstream Kyn metabolites in SIV-infected macaques (Boasso et al., 2009; Dunham et al., 2013). Taken together, elevated IDO activity in HIV infection and lifelong ART remain a risk for many health conditions, including chronic diseases, abnormalities in Trp metabolism, and neurological diseases (Sacktor, 2018).

\section{TRYPTOPHAN METABOLISM IN TUBERCULOSIS DISEASE}

Converging evidence shows that both innate and adaptive immune cells play an important role in controlling $M t b$ infection (North and Jung, 2004; Podinovskaia et al., 2013). Macrophages are the sentinel immune cells and the major target cells for $M t b$ infection, which are involved in recognition, phagocytosis, pathogen digestion, and induction of different activation pathways (proinflammatory M1 and anti-inflammatory M2 phenotypes). Cytolytic granule-secreting $\mathrm{T}$ cell responses also coordinate to reduce bacterial burdens (Mogues et al., 2001; Lazarevic and Flynn, 2002). Increasing evidence shows that Trp metabolism affects $M t b$ growth and activity (Qualls and Murray, 2016; Collins et al., 2020), as indicated by $M t b$-infected macrophage transcriptome profiling revealing high expression of several enzymes controlling Trp catabolism (Memari et al., 2015). During $M t b$ infection, IFN- $\gamma$-activated macrophages attempt to limit pathogen growth through Trp starvation, yet $M t b$ defends against this auxotroph threat by inducing Trp biosynthesis 


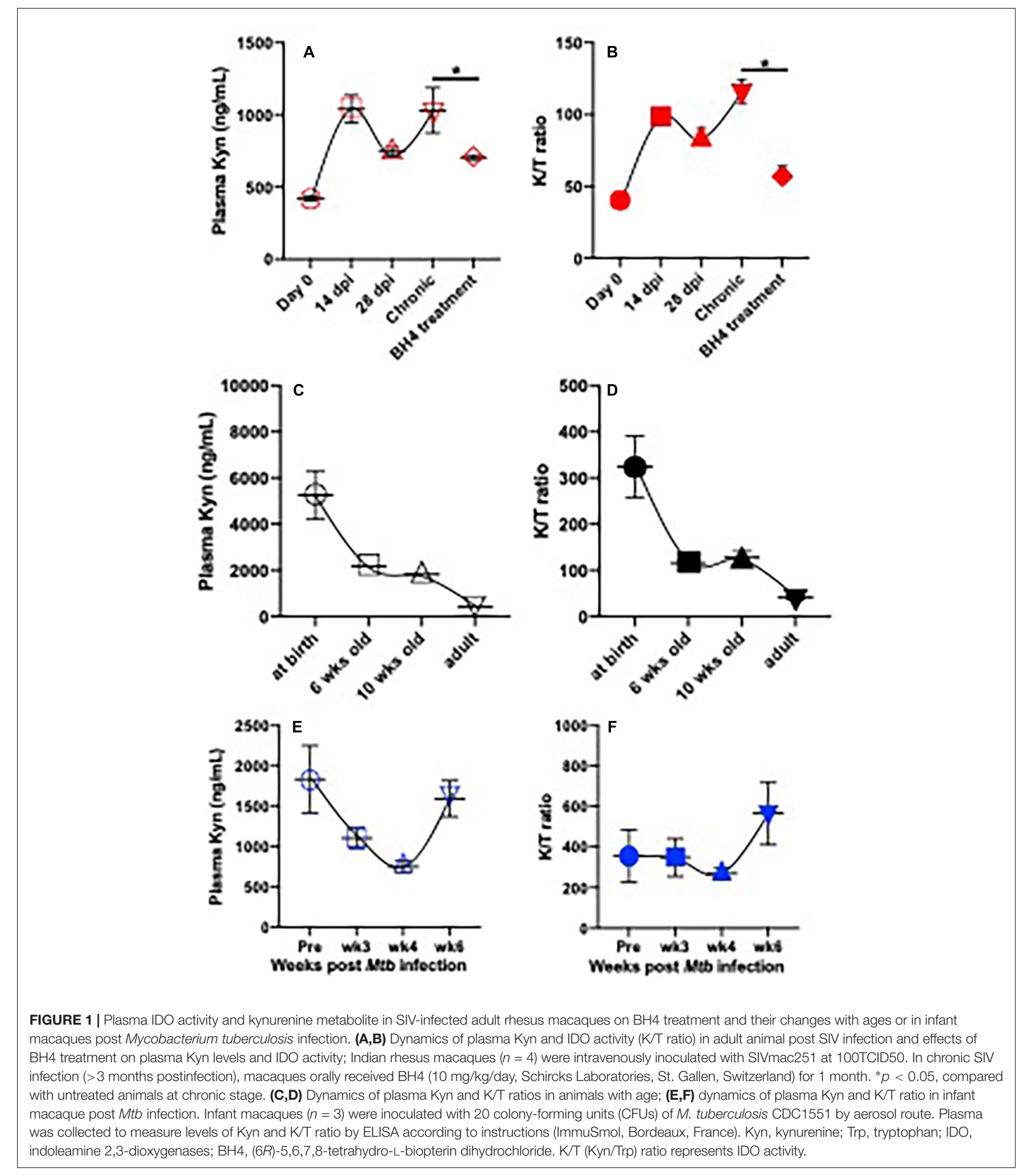

(Zhang et al., 2013; Berney and Berney-Meyer, 2017). In TB, granulomas formed in response to $M t b$ are immunological barriers to limit bacterial dissemination and growth (Ehlers and Schaible, 2012; Gideon et al., 2015). Notably, many metabolic events occur within the TB granuloma influencing the function of immune cells, potentially determining bacterial persistence or clearance. Increased IDO expression induced by IFN- $\gamma$ in $M t b$ infection can limit intracellular bacterial growth through 
degradation and starvation of Trp in systemic and anatomic tissues (Cowley and Elkins, 2003; Sakai et al., 2014; Khan et al., 2016). On the other hand, IDO-catalyzing Kyn metabolite is also involved in immunosuppression to avoid overwhelming tissue injury, leading to persistent bacterial infection.

In both active and latent TB disease, Trp metabolism is highly regulated to produce Kyn. Serum IDO activity is elevated in active TB patients than latently $M t b$-infected subjects (Weiner et al., 2012), which significantly declines in patients after standard TB treatment (Almeida et al., 2009; Suzuki et al., 2012), suggesting that IDO might be a potential target in TB disease. Therefore, IDO activity (Kyn/Trp ratio) and metabolite changes could be a predictor in the onset of $\mathrm{TB}$ and active $\mathrm{TB}$ disease (Collins et al., 2020). In addition, $M t b$ can also promote de novo synthesis of NAD + from Trp metabolite QUIN (Fricker et al., 2018). A nicotinamide analog, isoniazid (INH), is thus developed to be an effective anti-TB drug (Murray, 2003a), suggesting that Trp metabolites could be therapeutic targets for the $M t b$ treatment. Our previous study demonstrates the expression of IDO is highly induced in the lung of adult rhesus macaques, and that D1MT (IDO inhibitor) treatment could suppress IDO activity and reduce the bacterial burden in experimental $M t b$ infection (Gautam et al., 2018). Distinct from adult immune systems, developing infants are more vulnerable to $\mathrm{TB}$ infection and more prone to develop active diseases (Blusse van Oud-Alblas et al., 2002; Newton et al., 2008; Esposito et al., 2013; RoyaPabon and Perez-Velez, 2016; Kay et al., 2018). We examined levels of plasma Kyn and IDO activity (Kyn/Trp ratio) in uninfected infants after birth. The data showed that both were higher in plasma of newborns and then rapidly declined with age, reaching a low-level set point in adults (Figures 1C,D), likely causing active immunosuppression in early life (Medzhitov et al., 2012; Kollmann et al., 2017). Strikingly, Mtb infection in infant animals 3 months of age did not increase Kyn production and IDO activity within 4 weeks after $M t b$ inoculation but significantly promoted IDO-catalyzing Kyn accumulation by $\sim 6$ weeks, in concert with both elevated IDO activity and Kyn metabolites in $M t b$-infected infant animals at this time point (Figures 1E,F), indicating that treatment with IDO inhibitors may be a viable treatment strategy to test in $M t b$-infected infants. Although conventional anti-TB treatment may also reverse the IDO-mediated KP (Collins et al., 2020), the mechanisms at the intersection of Trp metabolism and TB in vivo are still unknown.

\section{TRYPTOPHAN METABOLISM IN Mtb/HIV COINFECTION}

$\mathrm{HIV} / \mathrm{Mtb}$ coinfection places a huge burden on public health, especially in resource-limited countries. This coinfection synergistically acts to impair immunological functions, devastating multiple aspects of host immunosurveillance (Getahun et al., 2010; Du Bruyn and Wilkinson, 2016; Day et al., 2017), as indicated by macrophage as reservoir for both pathogens and impaired differentiation and function of specific T cells (Geldmacher et al., 2010; Chetty et al., 2015; Kalokhe et al., 2015; Suarez et al., 2015; Day et al., 2017), leading to death if untreated. HIV-infected individuals without ART show a more than 20-fold higher risk to develop active TB disease than HIV-uninfected patients (Lawn and Zumla, 2011), as HIV infection predisposes the host to be susceptibility to $M t b$ infection and the incidence of TB disease (Mukadi et al., 1997; Palme et al., 2002). Although ART in HIV/Mtb coinfected patients reduces opportunistic infections and enhances $M t b$ specific $\mathrm{T}$ cell responses, it may not ameliorate TB diseases due to the paradoxical immune reconstitution inflammatory syndrome (IRIS) (Manosuthi et al., 2006; Lawn et al., 2007; Meintjes et al., 2008; Elliott et al., 2009; Namale et al., 2015). It is reported that HIV/Mtb coinfected patients display higher plasma IDO activity and more rapid TB disease progression from latent to active $\mathrm{TB}$, than do those with $\mathrm{TB}$ infection alone (Collins et al., 2020), suggesting that high IDO activity and Kyn-related metabolites are still maintained at high levels in HIV/Mtb coinfected individuals (du-Gyamfi et al., 2017), presumably generating similar function of Kyn metabolites to the HIV or $M t b$ infection. It remains unclear that such elevated IDO activity is caused by HIV and $M t b$ infection or implicated in progressive HIV and TB disease. TB treatment could reduce IDO activity in HIV + patients with TB, indicating plasma IDO activity is a biomarker of active TB in HIV-positive patients (du-Gyamfi et al., 2017). Since D1MT treatment shows discrepant effects of IDO inhibition in $M t b$ or SIV-infected macaques (Boasso et al., 2009; Dunham et al., 2013; Gautam et al., 2018), more IDO inhibitors are expected to test for their IDO inhibition in the $\mathrm{HIV} / \mathrm{Mtb}$ coinfection. Due to the minimal impact of ART on the KP pathway in HIV/SIV infection, it remains unknown whether treatment combined anti-HIV drugs with specific IDO inhibitor could be beneficial for containment of both pathogens in $\mathrm{HIV} / \mathrm{Mtb}$ coinfection. Trp metabolism in HIV/Mtb coinfection is currently less understood.

\section{INTERVENTIONS OF TRYPTOPHAN METABOLISM IN HIV/MTb INFECTION AND FUTURE PERSPECTIVES}

Given the critical role of Trp metabolism in HIV/Mtb infection, therapeutic interventions that target this pathway may reverse the presence of, or levels of, aberrant metabolites in these infectious diseases. To prevent KP and its downstream metabolites in the abnormal Trp metabolism, IDO inhibitors, which structurally mimic Trp substrate, such as Trp analogs D1MT (indoximod, IC50 > $2.5 \mathrm{mM})$, L-1-methyl-Trp (L1MT; IC50 = $120 \mu \mathrm{M})$, epacadostat $($ IC50 $=73 \mathrm{nM})$, and navoximod $($ IC50 $=28 \mathrm{nM})$, linrodostat $(\mathrm{IC} 50=3.4 \mathrm{nM})$, are applied in current clinical trials (Gunther et al., 2019). The IDO inhibition by 1-MTs in vivo might be ineffective and inadequate owing to their low affinity to the IDO enzyme and high dose required, as indicated by their high doses in a patient, which do not increase their serum levels (Soliman et al., 2014; Wirthgen et al., 2016; Gunther et al., 2019). Epacadostat is a higher potent IDO1 inhibitor, and oral administration of epacadostat with $100 \mathrm{mg}$ twice daily reaches a plasma concentration of $0.8 \mu \mathrm{M}$ on day 1 and $0.9 \mu \mathrm{M}$ on day 8 (Mitchell et al., 2018). Navoximod 


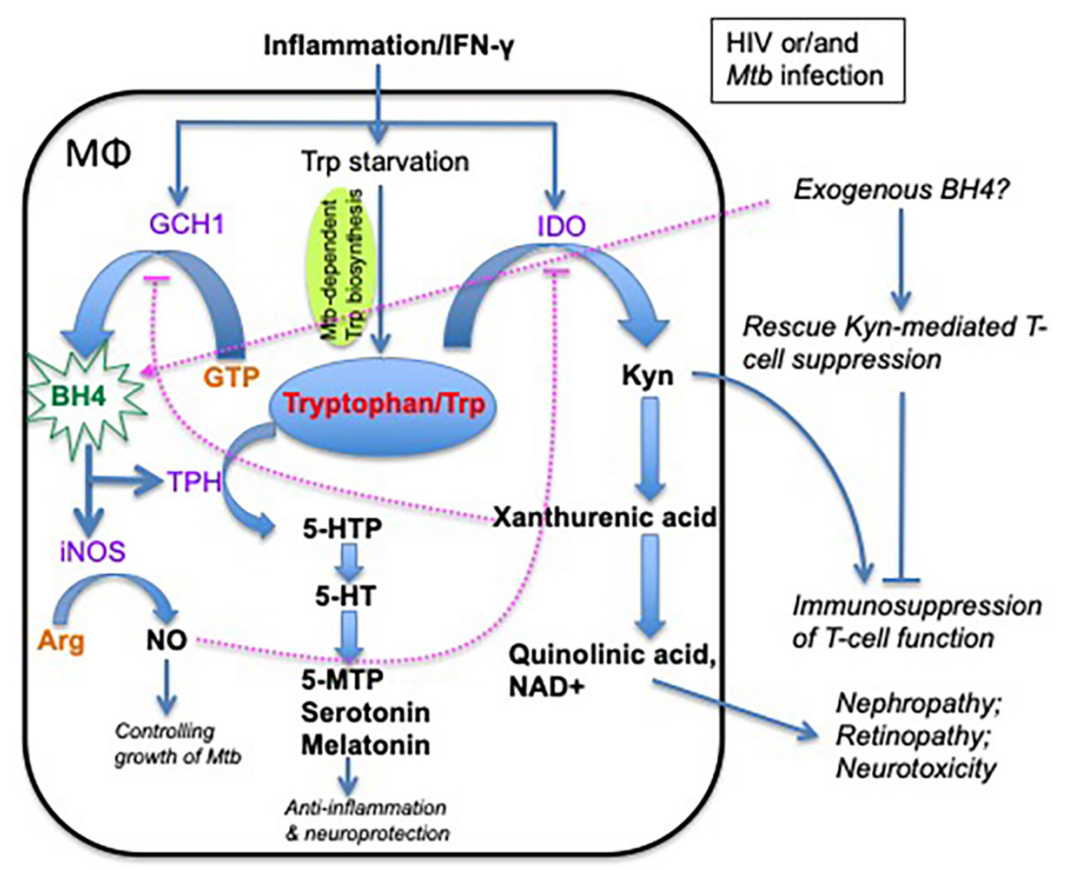

FIGURE 2 | Schematic of alternate tryptophan pathways and metabolites and their effects on macrophages, inflammation, and neurofunction. Tryptophan has two major metabolic pathways: (1) indoleamine 2,3-dioxygenase (IDO) pathway, which generates kynurenine-associated immunosuppression, and (2) tryptophan hydroxylase (TPH) pathway in which the tryptophan metabolites are involved in neural function modulation and anti-inflammatory effects. Note that tryptophan metabolism plays an important role in host immunity and neurological disorders in HIV/Mtb infection. BH4 is an essential enzyme cofactor for NOS in NO production, and THP in the conversion of tryptophan to 5-HTP. Importantly, NO strongly inhibits IDO1 activity, and exogenous BH4 may rescue kynurenine-mediated T-cell suppression. GCH1, GTP cyclohydrolase 1; BH4, tetrahydrobiopterin (one of tryptophan hydroxylase); 5-HTP, 5-hydroxytryptophan; 5-MTP, 5-methoxytryptophan; 5-HT, 5-hydroxytryptamine (serotonin); melatonin, $\mathrm{N}$-acetyl-5-hydroxytryptamine; TPH, tryptophan hydroxylase; IDO, indoleamine 2,3-dioxygenase; Kyn, kynurenine; NO, nitric oxide; iNOS, inducible nitric oxide synthase; NAD, nicotinamide adenine dinucleotide; D1MT, 1-methyl-D-tryptophan.

possesses dual inhibition of IDO1 and TDO as a potent drug for absorption and bioactivity by oral administration (Ebata et al., 2020). Linrodostat treatment as IDO inhibitor could reduce Kyn concentration by up to $90 \%$ (Zhang et al., 2021). Preclinical and clinical trials with IDO inhibitors are still being investigated.

In the context of HIV/Mtb infection, persistent proinflammatory responses may also activate GTP cyclohydrolase 1 (GCH1) to produce BH4 (Kapatos, 2013), probably mediating bactericidal activity and IDO inhibition via nitric oxide (NO) (Thomas et al., 2007; Jamaati et al., 2017; McNeill et al., 2018), promoting serotonin production for neuroprotection (Claeysen et al., 2015; Bethea et al., 2017) or other metabolites for anti-inflammatory mechanisms (Yang et al., 2015). It would be important to know whether altering the balance of Trp metabolism between two pathways (IDO or $\mathrm{TPH} / \mathrm{iNOS}$ activity) could provide an environment of effective immunity, bacterial killing, control of inflammation, and neuroprotection in $\mathrm{HIV}$ or/and $M t b$ infection. It is reported that treatment with exogenous $\mathrm{BH} 4$ can rescue $\mathrm{T}$-cell function from Kyn-mediated T-cell suppression, based on the fact that de novo BH4 synthesis is inhibited by Kyn metabolites per se (Zhang et al., 2013; Haruki et al., 2016), considering that BH4 has the potential to (1) promote NO production for bacterial killing; (2) block IDO/KP-mediated immunosuppression; (3) convert Trp metabolism to the TPH/serotonin pathway for neuroprotection and anti-inflammatory effects; and finally (4) rescue viral and bacterial T-cell immune responses (Figure 2) (Cronin et al., 2018; Fanet et al., 2020; Staats Pires et al., 2020). We hypothesize that exogenous $\mathrm{BH} 4$ immunotherapy may be a useful strategy to modulate Trp metabolism in HIV/Mtb-infected patients. However, further studies in animal models are clearly required to carefully evaluate whether such agents can modulate Trp metabolism to provide a safe and effective treatment for $\mathrm{HIV} / \mathrm{Mtb}$ coinfection.

\section{AUTHOR CONTRIBUTIONS}

XW wrote the manuscript. DK, SM, DK, RV, and HX revised the manuscript. All authors contributed to the article and approved the submitted version.

\section{FUNDING}

This work was supported by NIH Grants R01 HD099857, R01 AI147372, R01AI134245, and R21AI128130. The funders had no role in study design, data collection, analysis, decision to publish, or manuscript preparation. 


\section{REFERENCES}

Adigun, R., and Singh, R. (2020). Tuberculosis. Treasure Island, FL: StatPearls.

Almeida, A. S., Lago, P. M., Boechat, N., Huard, R. C., Lazzarini, L. C., Santos, A. R., et al. (2009). Tuberculosis is associated with a down-modulatory lung immune response that impairs Th1-type immunity. J. Immunol. 183, 718-731. doi: 10.4049/jimmunol.0801212

Alvarado, D. M., Chen, B., Iticovici, M., Thaker, A. I., Dai, N., VanDussen, K. L., et al. (2019). Epithelial indoleamine 2,3-dioxygenase 1 modulates aryl hydrocarbon receptor and notch signaling to increase differentiation of secretory cells and alter mucus-associated microbiota. Gastroenterology 157, 1093-1108e11. doi: 10.1053/j.gastro.2019. 07.013

Alzahrani, J., Hussain, T., Simar, D., Palchaudhuri, R., Abdel-Mohsen, M., Crowe, S. M., et al. (2019). Inflammatory and immunometabolic consequences of gut dysfunction in HIV: parallels with IBD and implications for reservoir persistence and non-AIDS comorbidities. EBioMedicine 46, 522-531. doi: 10. 1016/j.ebiom.2019.07.027

Babu, H., Sperk, M., Ambikan, A. T., Rachel, G., Viswanathan, V. K., Tripathy, S. P., et al. (2019). Plasma metabolic signature and abnormalities in HIV-infected individuals on long-term successful antiretroviral therapy. Metabolites 9:210. doi: 10.3390/metabo9100210

Badawy, A. A. (2017). Kynurenine pathway of tryptophan metabolism: regulatory and functional aspects. Int J Tryptophan Res 10:1178646917691938. doi: 10. $1177 / 1178646917691938$

Bandera, A., De Benedetto, I., Bozzi, G., and Gori, A. (2018). Altered gut microbiome composition in HIV infection: causes, effects and potential intervention. Curr. Opin. HIV AIDS 13, 73-80. doi: 10.1097/COH. 0000000000000429

Baran, H., Hainfellner, J. A., Kepplinger, B., Mazal, P. R., Schmid, H., and Budka, H. (2000). Kynurenic acid metabolism in the brain of HIV-1 infected patients. J. Neural Transm. (Vienna) 107, 1127-1138. doi: 10.1007/s00702007 0026

Barouch, D. H., and Deeks, S. G. (2014). Immunologic strategies for HIV-1 remission and eradication. Science 345, 169-174. doi: 10.1126/science. 1255512

Berney, M., and Berney-Meyer, L. (2017). Mycobacterium tuberculosis in the face of host-imposed nutrient limitation. Microbiol. Spectr. 5. doi: 10.1128/ microbiolspec.TBTB2-0030-2016

Bessede, A., Gargaro, M., Pallotta, M. T., Matino, D., Servillo, G., Brunacci, C., et al. (2014). Aryl hydrocarbon receptor control of a disease tolerance defence pathway. Nature 511, 184-190. doi: 10.1038/nature13323

Bethea, C. L., Reddy, A. P., and Christian, F. L. (2017). How studies of the serotonin system in macaque models of menopause relate to Alzheimer's disease1. J. Alzheimers Dis. 57, 1001-1015. doi: 10.3233/JAD-16 0601

Blusse van Oud-Alblas, H. J., van Vliet, M. E., Kimpen, J. L., de Villiers, G. S., Schaaf, H. S., and Donald, P. R. (2002). Human immunodeficiency virus infection in children hospitalised with tuberculosis. Ann. Trop. Paediatr. 22, 115-123. doi: 10.1179/027249302125000832

Boasso, A., Vaccari, M., Fuchs, D., Hardy, A. W., Tsai, W. P., Tryniszewska, E., et al. (2009). Combined effect of antiretroviral therapy and blockade of IDO in SIVinfected rhesus macaques. J. Immunol. 182, 4313-4320. doi: 10.4049/jimmunol. 0803314

Braidy, N., and Grant, R. (2017). Kynurenine pathway metabolism and neuroinflammatory disease. Neural Regen. Res. 12, 39-42. doi: 10.4103/16735374.198971

Brenchley, J. M., Price, D. A., Schacker, T. W., Asher, T. E., Silvestri, G., Rao, S., et al. (2006). Microbial translocation is a cause of systemic immune activation in chronic HIV infection. Nat. Med. 12, 1365-1371. doi: 10.1038/nm1511

Byakwaga, H., Boum, Y. II, Huang, Y., Muzoora, C., Kembabazi, A., Weiser, S. D., et al. (2014). The kynurenine pathway of tryptophan catabolism, CD4+ T-cell recovery, and mortality among HIV-infected ugandans initiating antiretroviral therapy. J. Infect. Dis. 210, 383-391. doi: 10.1093/infdis/j iu 115

Campbell, B. M., Charych, E., Lee, A. W., and Moller, T. (2014). Kynurenines in CNS disease: regulation by inflammatory cytokines. Front. Neurosci. 8:12. doi: $10.3389 /$ fnins. 2014.00012
Cervenka, I., Agudelo, L. Z., and Ruas, J. L. (2017). Kynurenines: tryptophan's metabolites in exercise, inflammation, and mental health. Science 357:eaaf9794. doi: 10.1126/science.aaf9794

Chen, J., Xun, J., Yang, J., Ji, Y., Liu, L., Qi, T., et al. (2019). Plasma indoleamine 2,3dioxygenase activity is associated with the size of the human immunodeficiency virus reservoir in patients receiving antiretroviral therapy. Clin. Infect. Dis. 68, 1274-1281. doi: 10.1093/cid/ciy676

Chetty, S., Govender, P., Zupkosky, J., Pillay, M., Ghebremichael, M., Moosa, M. Y., et al. (2015). Co-infection with mycobacterium tuberculosis impairs HIV-Specific CD8+ and CD4+ T cell functionality. PLoS One 10:e118654. doi: 10.1371/journal.pone.0118654

Claeysen, S., Bockaert, J., and Giannoni, P. (2015). Serotonin: a new hope in Alzheimer's disease? ACS Chem. Neurosci. 6, 940-943. doi: 10.1021/ acschemneuro.5b00135

Collins, J. M., Siddiqa, A., Jones, D. P., Liu, K., Kempker, R. R., Nizam, A., et al. (2020). Tryptophan catabolism reflects disease activity in human tuberculosis. JCI Insight 5:e137131. doi: 10.1172/jci.insight.137131

Cowley, S. C., and Elkins, K. L. (2003). CD4+ T cells mediate IFN-gammaindependent control of mycobacterium tuberculosis infection both in vitro and in vivo. J. Immunol. 171, 4689-4699.

Cronin, S. J. F., Seehus, C., Weidinger, A., Talbot, S., Reissig, S., Seifert, M., et al. (2018). The metabolite BH4 controls T cell proliferation in autoimmunity and cancer. Nature 563, 564-568. doi: 10.1038/s41586-018-0701-2

Curti, A., Trabanelli, S., Onofri, C., Aluigi, M., Salvestrini, V., Ocadlikova, D., et al. (2010). Indoleamine 2,3-dioxygenase-expressing leukemic dendritic cells impair a leukemia-specific immune response by inducing potent $\mathrm{T}$ regulatory cells. Haematologica 95, 2022-2030. doi: 10.3324/haematol.2010.02 5924

Dagenais-Lussier, X., Aounallah, M., Mehraj, V., El-Far, M., Tremblay, C., Sekaly, R. P., et al. (2016). Kynurenine reduces memory CD4 T-cell survival by interfering with interleukin-2 signaling early during HIV-1 infection. J. Virol. 90, 7967-7979. doi: 10.1128/JVI.00994-16

Day, C. L., Abrahams, D. A., Harris, L. D., van Rooyen, M., Stone, L., de Kock, M., et al. (2017). HIV-1 infection is associated with depletion and functional impairment of mycobacterium tuberculosis-specific CD4 T cells in individuals with latent tuberculosis infection. J. Immunol. 199, 2069-2080. doi: 10.4049/ jimmunol.1700558

DiNatale, B. C., Murray, I. A., Schroeder, J. C., Flaveny, C. A., Lahoti, T. S., Laurenzana, E. M., et al. (2010). Kynurenic acid is a potent endogenous aryl hydrocarbon receptor ligand that synergistically induces interleukin-6 in the presence of inflammatory signaling. Toxicol. Sci. 115, 89-97. doi: 10.1093/ toxsci/ $\mathrm{kfq} 024$

Douek, D. C., Roederer, M., and Koup, R. A. (2009). Emerging concepts in the immunopathogenesis of AIDS. Annu. Rev. Med. 60, 471-484. doi: 10.1146/ annurev.med.60.041807.123549

Drewes, J. L., Meulendyke, K. A., Liao, Z., Witwer, K. W., Gama, L., UbaidaMohien, C., et al. (2015). Quinolinic acid/tryptophan ratios predict neurological disease in SIV-infected macaques and remain elevated in the brain under CART. J. Neurovirol. 21, 449-463. doi: 10.1007/s13365-015-0334-2

Du Bruyn, E., and Wilkinson, R. J. (2016). The immune interaction between HIV1 infection and mycobacterium tuberculosis. Microbiol. Spectr. 4. doi: 10.1128/ microbiolspec.TBTB2-0012-2016

du-Gyamfi, C. G. A., Snyman, T., Hoffmann, C. J., Martinson, N. A., Chaisson, R. E., George, J. A., et al. (2017). Plasma indoleamine 2, 3dioxygenase, a biomarker for tuberculosis in human immunodeficiency virus-infected patients. Clin. Infect. Dis. 65, 1356-1358. doi: 10.1093/cid/ $\operatorname{cix} 550$

Dunham, R. M., Gordon, S. N., Vaccari, M., Piatak, M., Huang, Y., Deeks, S. G., et al. (2013). Preclinical evaluation of HIV eradication strategies in the simian immunodeficiency virus-infected rhesus macaque: a pilot study testing inhibition of indoleamine 2,3-dioxygenase. AIDS Res. Hum. Retroviruses 29, 207-214. doi: 10.1089/AID.2012.0162

Ebata, T., Shimizu, T., Fujiwara, Y., Tamura, K., Kondo, S., Iwasa, S., et al. (2020). Phase I study of the indoleamine 2,3-dioxygenase 1 inhibitor navoximod (GDC-0919) as monotherapy and in combination with the PD-L1 inhibitor atezolizumab in Japanese patients with advanced solid tumours. Invest. New Drugs 38, 468-477. doi: 10.1007/s10637-019-00787-3 
Eggers, C., Arendt, G., Hahn, K., Husstedt, I. W., Maschke, M., Neuen-Jacob, E., et al. (2017). HIV-1-associated neurocognitive disorder: epidemiology, pathogenesis, diagnosis, and treatment. J. Neurol. 264, 1715-1727. doi: 10.1007/ s00415-017-8503-2

Ehlers, S., and Schaible, U. E. (2012). The granuloma in tuberculosis: dynamics of a host-pathogen collusion. Front. Immunol. 3:411. doi: 10.3389/fimmu.2012. 00411

Elliott, J. H., Vohith, K., Saramony, S., Savuth, C., Dara, C., Sarim, C., et al. (2009). Immunopathogenesis and diagnosis of tuberculosis and tuberculosis-associated immune reconstitution inflammatory syndrome during early antiretroviral therapy. J. Infect. Dis. 200, 1736-1745. doi: 10.1086/644784

Esposito, S., Tagliabue, C., and Bosis, S. (2013). Tuberculosis in children. Mediterr. J. Hematol. Infect. Dis. 5:e2013064. doi: 10.4084/MJHID.2013.064

Estes, J. D., LeGrand, R., and Petrovas, C. (2018). Visualizing the immune system: providing key insights into HIV/SIV infections. Front. Immunol. 9:423. doi: 10.3389/fimmu.2018.00423

Fanet, H., Capuron, L., Castanon, N., Calon, F., and Vancassel, S. (2020). Tetrahydrobioterin (BH4) pathway: from metabolism to neuropsychiatry. Curr. Neuropharmacol. 19, 591-609. doi: 10.2174/1570159X18666200729103529

Favre, D., Mold, J., Hunt, P. W., Kanwar, B., Loke, P., Seu, L., et al. (2010). Tryptophan catabolism by indoleamine 2,3-dioxygenase 1 alters the balance of TH17 to regulatory T cells in HIV disease. Sci. Transl. Med. 2:32ra36. doi: 10.1126/scitranslmed.3000632

Ferrell, D., and Giunta, B. (2014). The impact of HIV-1 on neurogenesis: implications for HAND. Cell Mol. Life Sci. 71, 4387-4392. doi: 10.1007/s00018014-1702-4

Fricker, R. A., Green, E. L., Jenkins, S. I., and Griffin, S. M. (2018). The Influence of nicotinamide on health and disease in the central nervous system. Int. J. Tryptophan Res. 11:1178646918776658. doi: 10.1177/1178646918776658

Gautam, U. S., Foreman, T. W., Bucsan, A. N., Veatch, A. V., Alvarez, X., Adekambi, T., et al. (2018). In vivo inhibition of tryptophan catabolism reorganizes the tuberculoma and augments immune-mediated control of mycobacterium tuberculosis. Proc. Natl. Acad. Sci. U.S.A. 115, E62-E71. doi: $10.1073 /$ pnas. 1711373114

Geldmacher, C., Ngwenyama, N., Schuetz, A., Petrovas, C., Reither, K., Heeregrave, E. J., et al. (2010). Preferential infection and depletion of mycobacterium tuberculosis-specific CD4 T cells after HIV-1 infection. J. Exp. Med. 207, 2869-2881. doi: 10.1084/jem.20100090

Getahun, H., Gunneberg, C., Granich, R., and Nunn, P. (2010). HIV infectionassociated tuberculosis: the epidemiology and the response. Clin. Infect. Dis. 50(Suppl. 3), S201-S207. doi: 10.1086/651492

Gideon, H. P., Phuah, J., Myers, A. J., Bryson, B. D., Rodgers, M. A., Coleman, M. T., et al. (2015). Variability in tuberculosis granuloma $T$ cell responses exists, but a balance of pro- and anti-inflammatory cytokines is associated with sterilization. PLoS Pathog. 11:e1004603. doi: 10.1371/journal.ppat.100 4603

Gostner, J. M., Becker, K., Kurz, K., and Fuchs, D. (2015). Disturbed amino acid metabolism in HIV: association with neuropsychiatric symptoms. Front. Psychiatry 6:97. doi: 10.3389/fpsyt.2015.00097

Gunther, J., Dabritz, J., and Wirthgen, E. (2019). Limitations and off-target effects of tryptophan-related IDO inhibitors in cancer treatment. Front. Immunol. 10:1801. doi: 10.3389/fimmu.2019.01801

Haruki, H., Hovius, R., Pedersen, M. G., and Johnsson, K. (2016). Tetrahydrobiopterin biosynthesis as a potential target of the kynurenine pathway metabolite xanthurenic acid. J. Biol. Chem. 291, 652-657. doi: 10.1074/jbc.C115.680488

Huengsberg, M., Winer, J. B., Gompels, M., Round, R., Ross, J., and Shahmanesh, M. (1998). Serum kynurenine-to-tryptophan ratio increases with progressive disease in HIV-infected patients. Clin. Chem. 44, 858-862.

Jamaati, H., Mortaz, E., Pajouhi, Z., Folkerts, G., Movassaghi, M., Moloudizargari, M., et al. (2017). Nitric oxide in the pathogenesis and treatment of tuberculosis. Front. Microbiol. 8:2008. doi: 10.3389/fmicb.2017.02008

Jenabian, M. A., El-Far, M., Vyboh, K., Kema, I., Costiniuk, C. T., Thomas, R., et al. (2015). Immunosuppressive tryptophan catabolism and gut mucosal dysfunction following early HIV infection. J. Infect. Dis. 212, 355-366. doi: 10.1093/infdis/jiv037

Jenabian, M. A., Patel, M., Kema, I., Kanagaratham, C., Radzioch, D., Thebault, P., et al. (2013). Distinct tryptophan catabolism and Th17/Treg balance in HIV progressors and elite controllers. PLoS One 8:e78146. doi: 10.1371/journal.pone. 0078146

Kalokhe, A. S., Adekambi, T., Ibegbu, C. C., Ray, S. M., Day, C. L., and Rengarajan, J. (2015). Impaired degranulation and proliferative capacity of Mycobacterium tuberculosis-specific CD8+ T cells in HIV-infected individuals with latent tuberculosis. J. Infect. Dis. 211, 635-640. doi: 10.1093/infdis/ jiu505

Kapatos, G. (2013). The neurobiology of tetrahydrobiopterin biosynthesis: a model for regulation of GTP cyclohydrolase I gene transcription within nigrostriatal dopamine neurons. IUBMB Life 65, 323-333. doi: 10.1002/iub.1140

Kay, A., Garcia-Prats, A. J., and Mandalakas, A. M. (2018). HIV-associated pediatric tuberculosis: prevention, diagnosis and treatment. Curr. Opin. HIV AIDS 13, 501-506. doi: 10.1097/COH.0000000000000500

Keegan, M. R., Chittiprol, S., Letendre, S. L., Winston, A., Fuchs, D., Boasso, A., et al. (2016). Tryptophan metabolism and its relationship with depression and cognitive impairment among HIV-infected individuals. Int. J. Tryptophan Res. 9, 79-88. doi: 10.4137/IJTR.S36464

Keegan, M. R., Winston, A., Higgs, C., Fuchs, D., Boasso, A., and Nelson, M. (2019). Tryptophan metabolism and its relationship with central nervous system toxicity in people living with HIV switching from efavirenz to dolutegravir. J. Neurovirol. 25, 85-90. doi: 10.1007/s13365-0180688-3

Khan, T. A., Mazhar, H., Saleha, S., Tipu, H. N., Muhammad, N., and Abbas, M. N. (2016). Interferon-gamma improves macrophages function against $\mathrm{m}$. tuberculosis in multidrug-resistant tuberculosis patients. Chemother. Res. Pract. 2016:7295390. doi: 10.1155/2016/7295390

Kim, J. S., Kim, Y. R., and Yang, C. S. (2020). Host-directed therapy in tuberculosis: targeting host metabolism. Front. Immunol. 11:1790. doi: 10.3389/fimmu.2020. 01790

Kollmann, T. R., Kampmann, B., Mazmanian, S. K., Marchant, A., and Levy, O. (2017). Protecting the newborn and young infant from infectious diseases: lessons from immune ontogeny. Immunity 46, 350-363. doi: 10.1016/j.immuni. 2017.03.009

Lawn, S. D., Myer, L., Bekker, L. G., and Wood, R. (2007). Tuberculosis-associated immune reconstitution disease: incidence, risk factors and impact in an antiretroviral treatment service in South Africa. AIDS 21, 335-341. doi: 10. 1097/QAD.0b013e328011efac

Lawn, S. D., and Zumla, A. I. (2011). Tuberculosis. Lancet 378, 57-72. doi: 10.1016/ S0140-6736(10)62173-3

Lazarevic, V., and Flynn, J. (2002). CD8+ T cells in tuberculosis. Am. J. Respir. Crit. Care Med. 166, 1116-1121. doi: 10.1164/rccm.2204027

Lovelace, M. D., Varney, B., Sundaram, G., Lennon, M. J., Lim, C. K., Jacobs, K., et al. (2017). Recent evidence for an expanded role of the kynurenine pathway of tryptophan metabolism in neurological diseases. Neuropharmacology $112(\mathrm{Pt}$ B), 373-388. doi: 10.1016/j.neuropharm.2016.03.024

Mandi, Y., and Vecsei, L. (2012). The kynurenine system and immunoregulation. J. Neural. Transm. (Vienna) 119, 197-209. doi: 10.1007/s00702-011-0681-y

Manosuthi, W., Kiertiburanakul, S., Phoorisri, T., and Sungkanuparph, S. (2006). Immune reconstitution inflammatory syndrome of tuberculosis among HIVinfected patients receiving antituberculous and antiretroviral therapy. J. Infect. 53, 357-363. doi: 10.1016/j.jinf.2006.01.002

McNeill, E., Stylianou, E., Crabtree, M. J., Harrington-Kandt, R., Kolb, A. L., Diotallevi, M., et al. (2018). Regulation of mycobacterial infection by macrophage Gch1 and tetrahydrobiopterin. Nat. Commun. 9:5409. doi: 10. 1038/s41467-018-07714-9

Medzhitov, R., Schneider, D. S., and Soares, M. P. (2012). Disease tolerance as a defense strategy. Science 335, 936-941. doi: 10.1126/science.1214935

Meintjes, G., Lawn, S. D., Scano, F., Maartens, G., French, M. A., Worodria, W., et al. (2008). Tuberculosis-associated immune reconstitution inflammatory syndrome: case definitions for use in resource-limited settings. Lancet Infect. Dis. 8, 516-523. doi: 10.1016/S1473-3099(08)70184-1

Meltzer, C. C., Smith, G., DeKosky, S. T., Pollock, B. G., Mathis, C. A., Moore, R. Y., et al. (1998). Serotonin in aging, late-life depression, and Alzheimer's disease: the emerging role of functional imaging. Neuropsychopharmacology 18 , 407-430. doi: 10.1016/S0893-133X(97)00194-2

Memari, B., Bouttier, M., Dimitrov, V., Ouellette, M., Behr, M. A., Fritz, J. H., et al. (2015). Engagement of the aryl hydrocarbon receptor in mycobacterium tuberculosis-infected macrophages has pleiotropic effects on innate 
immune signaling. J. Immunol. 195, 4479-4491. doi: 10.4049/jimmunol.150 1141

Mitchell, T. C., Hamid, O., Smith, D. C., Bauer, T. M., Wasser, J. S., Olszanski, A. J., et al. (2018). Epacadostat plus pembrolizumab in patients with advanced solid tumors: phase I results from a multicenter, open-label phase I/II trial (ECHO202/KEYNOTE-037). J. Clin. Oncol. 36, 3223-3230. doi: 10.1200/JCO.2018.78. 9602

Mogues, T., Goodrich, M. E., Ryan, L., LaCourse, R., and North, R. J. (2001). The relative importance of $\mathrm{T}$ cell subsets in immunity and immunopathology of airborne mycobacterium tuberculosis infection in mice. J. Exp. Med. 193, 271-280.

Mukadi, Y. D., Wiktor, S. Z., Coulibaly, I. M., Coulibaly, D., Mbengue, A., Folquet, A. M., et al. (1997). Impact of HIV infection on the development, clinical presentation, and outcome of tuberculosis among children in Abidjan, Cote d'Ivoire. AIDS 11, 1151-1158.

Murray, M. F. (2003a). Nicotinamide: an oral antimicrobial agent with activity against both mycobacterium tuberculosis and human immunodeficiency virus. Clin. Infect. Dis. 36, 453-460. doi: 10.1086/367544

Murray, M. F. (2003b). Tryptophan depletion and HIV infection: a metabolic link to pathogenesis. Lancet Infect. Dis. 3, 644-652. doi: 10.1016/s1473-3099(03) 00773-4

Namale, P. E., Abdullahi, L. H., Fine, S., Kamkuemah, M., Wilkinson, R. J., and Meintjes, G. (2015). Paradoxical TB-IRIS in HIV-infected adults: a systematic review and meta-analysis. Future Microbiol. 10, 1077-1099. doi: 10.2217/fmb. 15.9

Newton, S. M., Brent, A. J., Anderson, S., Whittaker, E., and Kampmann, B. (2008). Paediatric tuberculosis. Lancet Infect. Dis. 8, 498-510. doi: 10.1016/ S1473-3099(08)70182-8

North, R. J., and Jung, Y. J. (2004). Immunity to tuberculosis. Annu. Rev. Immunol. 22, 599-623. doi: 10.1146/annurev.immunol.22.012703.104635

Pallotta, M. T., Orabona, C., Volpi, C., Vacca, C., Belladonna, M. L., Bianchi, R., et al. (2011). Indoleamine 2,3-dioxygenase is a signaling protein in longterm tolerance by dendritic cells. Nat. Immunol. 12, 870-878. doi: 10.1038/ni. 2077

Palme, I. B., Gudetta, B., Bruchfeld, J., Muhe, L., and Giesecke, J. (2002). Impact of human immunodeficiency virus 1 infection on clinical presentation, treatment outcome and survival in a cohort of ethiopian children with tuberculosis. Pediatr. Infect. Dis. J. 21, 1053-1061. doi: 10.1097/01.inf.0000036090.75 $121 . \mathrm{f3}$

Podinovskaia, M., Lee, W., Caldwell, S., and Russell, D. G. (2013). Infection of macrophages with mycobacterium tuberculosis induces global modifications to phagosomal function. Cell Microbiol. 15, 843-859. doi: 10.1111/cmi.12092

Qualls, J. E., and Murray, P. J. (2016). Immunometabolism within the tuberculosis granuloma: amino acids, hypoxia, and cellular respiration. Semin. Immunopathol. 38, 139-152. doi: 10.1007/s00281-015-0534-0

Rodriguez Cetina, B. H., Vasudevan, A., and Elkhal, A. (2017). Aspects of tryptophan and nicotinamide adenine dinucleotide in immunity: a new twist in an old tale. Int. J. Tryptophan Res. 10:1178646917713491. doi: 10.1177/ 1178646917713491

Routy, J. P., Mehraj, V., Vyboh, K., Cao, W., Kema, I., and Jenabian, M. A. (2015). Clinical relevance of kynurenine pathway in HIV/AIDS: an immune checkpoint at the crossroads of metabolism and inflammation. AIDS Rev. 17, 96-106.

Roya-Pabon, C. L., and Perez-Velez, C. M. (2016). Tuberculosis exposure, infection and disease in children: a systematic diagnostic approach. Pneumonia (Nathan) 8:23. doi: 10.1186/s41479-016-0023-9

Ruhe, H. G., Mason, N. S., and Schene, A. H. (2007). Mood is indirectly related to serotonin, norepinephrine and dopamine levels in humans: a meta-analysis of monoamine depletion studies. Mol. Psychiatry 12, 331-359. doi: 10.1038/sj.mp. 4001949

Sacktor, N. (2018). Changing clinical phenotypes of HIV-associated neurocognitive disorders. J. Neurovirol. 24, 141-145. doi: 10.1007/s13365-017-0556-6

Sakai, S., Mayer-Barber, K. D., and Barber, D. L. (2014). Defining features of protective CD4 $\mathrm{T}$ cell responses to mycobacterium tuberculosis. Curr. Opin. Immunol. 29, 137-142. doi: 10.1016/j.coi.2014.06.003

Sankaran, S., George, M. D., Reay, E., Guadalupe, M., Flamm, J., Prindiville, T., et al. (2008). Rapid onset of intestinal epithelial barrier dysfunction in primary human immunodeficiency virus infection is driven by an imbalance between immune response and mucosal repair and regeneration. J. Virol. 82, 538-545. doi: 10.1128/JVI.01449-07

Schmidt, S. V., and Schultze, J. L. (2014). New insights into IDO biology in bacterial and viral infections. Front. Immunol. 5:384. doi: 10.3389/fimmu.2014.00384

Schroecksnadel, K., Sarcletti, M., Winkler, C., Mumelter, B., Weiss, G., Fuchs, D., et al. (2008). Quality of life and immune activation in patients with HIV-infection. Brain Behav. Immun. 22, 881-889. doi: 10.1016/j.bbi.2007. 12.011

Schroecksnadel, K., Zangerle, R., Bellmann-Weiler, R., Garimorth, K., Weiss, G., and Fuchs, D. (2007). Indoleamine-2, 3-dioxygenase and other interferongamma-mediated pathways in patients with human immunodeficiency virus infection. Curr. Drug Metab. 8, 225-236. doi: 10.2174/138920007780362608

Smith, D. G., Guillemin, G. J., Pemberton, L., Kerr, S., Nath, A., Smythe, G. A., et al. (2001). Quinolinic acid is produced by macrophages stimulated by platelet activating factor. Nef and Tat. J. Neurovirol. 7, 56-60. doi: 10.1080/ 135502801300069692

Soliman, H. H., Jackson, E., Neuger, T., Dees, E. C., Harvey, R. D., Han, H., et al. (2014). A first in man phase I trial of the oral immunomodulator, indoximod, combined with docetaxel in patients with metastatic solid tumors. Oncotarget 5, 8136-8146. doi: 10.18632/oncotarget.2357

Staats Pires, A., Heng, B., Tan, V. X., Latini, A., Russo, M. A., Santarelli, D. M., et al. (2020). Kynurenine, tetrahydrobiopterin, and cytokine inflammatory biomarkers in individuals affected by diabetic neuropathic pain. Front. Neurosci. 14:890. doi: 10.3389/fnins.2020.00890

Suarez, G. V., Angerami, M. T., Vecchione, M. B., Laufer, N., Turk, G., Ruiz, M. J., et al. (2015). HIV-TB coinfection impairs CD8(+) T-cell differentiation and function while dehydroepiandrosterone improves cytotoxic antitubercular immune responses. Eur. J. Immunol. 45, 2529-2541. doi: 10.1002/eji.2015 45545

Suzuki, Y., Suda, T., Asada, K., Miwa, S., Suzuki, M., Fujie, M., et al. (2012). Serum indoleamine 2,3-dioxygenase activity predicts prognosis of pulmonary tuberculosis. Clin. Vaccine Immunol. 19, 436-442. doi: 10.1128/CVI.05402-11

Thomas, S. R., Terentis, A. C., Cai, H., Takikawa, O., Levina, A., Lay, P. A., et al. (2007). Post-translational regulation of human indoleamine 2,3-dioxygenase activity by nitric oxide. J. Biol. Chem. 282, 23778-23787. doi: 10.1074/jbc. M700669200

van Laarhoven, A., Dian, S., Aguirre-Gamboa, R., vila-Pacheco, J. A., RicanoPonce, I., Ruesen, C., et al. (2018). Cerebral tryptophan metabolism and outcome of tuberculous meningitis: an observational cohort study. Lancet Infect. Dis. 18, 526-535. doi: 10.1016/S1473-3099(18)30053-7

Veazey, R. S., DeMaria, M., Chalifoux, L. V., Shvetz, D. E., Pauley, D. R., Knight, H. L., et al. (1998). Gastrointestinal tract as a major site of CD4+ T cell depletion and viral replication in SIV infection. Science 280, 427-431. doi: $10.1126 /$ science. 280.5362 .427

Ventura, J. D. (2020). Human Immunodeficiency Virus 1 (HIV-1): viral latency, the reservoir, and the cure. Yale J. Biol. Med. 93, 549-560.

Vujkovic-Cvijin, I., Dunham, R. M., Iwai, S., Maher, M. C., Albright, R. G., Broadhurst, M. J., et al. (2013). Dysbiosis of the gut microbiota is associated with HIV disease progression and tryptophan catabolism. Sci. Transl. Med. 5:193ra91. doi: 10.1126/scitranslmed.3006438

Wang, X., and Xu, H. (2018). Potential epigenetic regulation in the germinal center reaction of lymphoid tissues in HIV/SIV infection. Front. Immunol. 9:159. doi: 10.3389/fimmu.2018.00159

Weiner, J. III, Parida, S. K., Maertzdorf, J., Black, G. F., Repsilber, D., Telaar, A., et al. (2012). Biomarkers of inflammation, immunosuppression and stress with active disease are revealed by metabolomic profiling of tuberculosis patients. PLoS One 7:e40221. doi: 10.1371/journal.pone.004 0221

Wirthgen, E., Kanitz, E., Tuchscherer, M., Tuchscherer, A., Domanska, G., Weitschies, W., et al. (2016). Pharmacokinetics of 1-methyl-L-tryptophan after single and repeated subcutaneous application in a porcine model. Exp. Anim. 65, 147-155. doi: 10.1538/expanim.15-0096

Wu, K. K., Cheng, H. H., and Chang, T. C. (2014). 5-methoxyindole metabolites of L-tryptophan: control of COX-2 expression, inflammation and tumorigenesis. J. Biomed. Sci. 21:17. doi: 10.1186/1423-0127-21-17

Xu, H., Wang, X., and Veazey, R. S. (2013). Mucosal immunology of HIV infection. Immunol. Rev. 254, 10-33. doi: 10.1111/imr.12072 
Yang, T. H., Hsu, P. Y., Meng, M., and Su, C. C. (2015). Supplement of 5hydroxytryptophan before induction suppresses inflammation and collageninduced arthritis. Arthritis Res. Ther. 17:364. doi: 10.1186/s13075-015$0884-y$

Zhang, L., Cherney, E. C., Zhu, X., Lin, T. A., Gullo-Brown, J., Maley, D., et al. (2021). Discovery of imidazopyridines as potent inhibitors of indoleamine 2,3dioxygenase 1 for cancer immunotherapy. ACS Med. Chem. Lett. 12, 494-501. doi: 10.1021/acsmedchemlett.1c00014

Zhang, Y. J., Reddy, M. C., Ioerger, T. R., Rothchild, A. C., Dartois, V., Schuster, B. M., et al. (2013). Tryptophan biosynthesis protects mycobacteria from CD4 T-cell-mediated killing. Cell 155, 1296-1308. doi: 10.1016/j.cell.2013.10.045
Conflict of Interest: The authors declare that the research was conducted in the absence of any commercial or financial relationships that could be construed as a potential conflict of interest.

Copyright $\odot 2021$ Wang, Mehra, Kaushal, Veazey and Xu. This is an open-access article distributed under the terms of the Creative Commons Attribution License (CC BY). The use, distribution or reproduction in other forums is permitted, provided the original author(s) and the copyright owner(s) are credited and that the original publication in this journal is cited, in accordance with accepted academic practice. No use, distribution or reproduction is permitted which does not comply with these terms. 